\title{
Antidepressant Medication Use for Primary Care Patients with and without Medical Comorbidities: A National Electronic Health Record (EHR) Network Study
}

\author{
James M. Gill, MD, MPH, Michael S. Klinkman, MS, MD, and Ying Xia Chen, MS
}

Background: Because comorbid depression can complicate medical conditions (eg, diabetes), physicians may treat depression more aggressively in patients who have these conditions. This study examined whether primary care physicians prescribe antidepressant medications more often and in higher doses for persons with medical comorbidities.

Methods: This secondary data analysis of electronic health record data was conducted in the Centricity Health Care User Research Network (CHURN), a national network of ambulatory practices that use a common outpatient electronic health record. Participants included 209 family medicine and general internal medicine providers in 40 primary care CHURN offices in 17 US states. Patients included adults with a new episode of depression that had been diagnosed during the period october 2006 through July $2007(n=1513)$. Prescription of antidepressant medication and doses of antidepressant medication were compared for patients with and without 6 comorbid conditions: diabetes, coronary heart disease, congestive heart failure, cerebrovascular disease, chronic obstructive pulmonary disease, and cancer.

Results: $20.7 \%$ of patients had at least one medical comorbidity whereas $5.8 \%$ had multiple comorbidities. Overall, $77 \%$ of depressed patients were prescribed antidepressant medication. After controlling for age and sex, patients with multiple comorbidities were less likely to be prescribed medication (adjusted odds ratio, $0.58 ; 95 \%$ CI, 0.35-0.96), but there was no significant difference by individual comorbidities. Patients with cerebrovascular disease were less likely to be prescribed a full dose of medication (adjusted odds ratio, 0.26 ; 95\% CI, $0.08-0.88$ ), but there were no differences for other comorbidities or for multiple comorbidities, and there was no difference for any comorbidities in the prescription of minimally effective doses.

Conclusions: Patients with new episodes of depression who present to a primary care practice are not treated more aggressively if they have medical comorbidities. In fact, patients with multiple comorbidities are treated somewhat less aggressively. (J Am Board Fam Med 2010;23:499-508.)

Keywords: Practice-based Research, PBRN, Electronic Medical Records, Primary Health Care, Chronic Disease

Depression is among the most common chronic conditions seen in primary care, with nearly $17 \%$ of

This article was externally peer reviewed.

Submitted 31 December 2009; revised 4 May 2010; accepted 6 May 2010.

From Delaware Valley Outcomes Research, Newark, DE (JMG, YXC); the Department of Family and Community Medicine, Thomas Jefferson University, Philadelphia, PA (JMG); the Department of Family Medicine, St. Francis Hospital, Wilmington, DE (JMG); and the Departments of Family and Community Medicine and the Department of Psychiatry, University of Michigan, Ann Arbor (MSK).

Funding: This study was funded by Wyeth Pharmaceuticals (Collegeville, PA).

\footnotetext{
See Related Commentary on Page 429.
}

the adult population in the community meeting criteria for major depressive disorder (MDD) during their lifetime ${ }^{1}$ and nearly $7 \%$ experiencing MDD during a 12 -month period. ${ }^{2}$ The prevalence of MDD is even higher among those persons who receive care in the primary care setting, ${ }^{3}$ which is where most persons who seek care for their depression receive this care. ${ }^{3,4}$

Although depression is common among all populations, it is more common in persons with chronic medical conditions. ${ }^{5}$ In particular, studies

Conflict of interest: Dr. Gill was a consultant for GE Healthcare.

Corresponding author: James M. Gill, MD, MPH, Delaware Valley Outcomes Research, 17 Henderson Hill Road, Newark, DE 19711 (E-mail: gillj@dvoresearch.com). 
have shown the prevalence of depression to be higher for persons with diabetes mellitus, ${ }^{6,7}$ heart disease, ${ }^{8-11}$ stroke $^{7}$ chronic obstructive pulmonary disease (COPD), ${ }^{12}$ and cancer. ${ }^{13-15}$

Comorbid depression can exacerbate the chronic medical condition or even increase mortality in persons with these chronic medical conditions. For example, studies have shown that depression is associated with worse glycemic control ${ }^{16}$ and higher mortality ${ }^{17,18}$ in those with diabetes; higher morbidity ${ }^{19}$ and mortality ${ }^{20}$ in patients after myocardial infarction; higher rates of hospitalization among stroke patients; ${ }^{21}$ and reduced survival among cancer patients. ${ }^{22}$ Therefore, some authors have argued that physicians should be particularly vigilant in the diagnosis and treatment of depression in persons with chronic diseases such as cancer $^{23}$ and heart disease. ${ }^{10}$

However, there is little evidence that primary care physicians treat depression more aggressively in patients who have comorbid medical conditions. It could be that physicians actually treat depression less aggressively in patients who have serious comorbidities, partly because of concerns about the adverse effects of antidepressant medications. ${ }^{8,24}$ One recent study found that depressed patients who had diabetes were more likely to be prescribed antidepressant medications than patients who did not have diabetes, but patients who had coronary heart disease (CHD) were less likely to be prescribed antidepressant medications and that there was no difference for patients who had cancer or cerebrovascular disease (CVD). ${ }^{25}$ However, that study was limited in its applicability to primary care because many of the physicians studied were specialists who do not normally treat depression.

The purpose of this analysis was to examine antidepressant treatment for patients who experienced new episodes of depression and were diagnosed in primary care offices that are part of a national research network. It was hypothesized that these patients would be more likely to be treated with antidepressants if they had chronic comorbid medical conditions including diabetes, CHD, congestive heart failure, CVD, COPD, or cancer. Second, it was hypothesized that patients who had comorbid medical conditions would be more likely to be treated with higher doses of antidepressant medications than patients who did not have these comorbid conditions.

\section{Methods}

\section{Study Setting and Participants}

This was a retrospective cohort study from a national research network called the Centricity Health Care User Research Network (CHURN). CHURN is a network of physicians and other providers in ambulatory practices that use a particular outpatient electronic health record (EHR), Centricity Provider Office (GE Healthcare, Waukesha, WI), and that have agreed to share data and participate in quality of care studies. CHURN members share data through the Medical Quality Improvement Consortium. Each office that participates in the Medical Quality Improvement Consortium regularly uploads de-identified clinical data into a central, secure repository. These data include demographic information, medications and prescriptions, diagnoses or problems, laboratory results, and other clinical data such as blood pressure, weight, and physical examination findings. The data are then cleaned, standardized, and put into a central data repository. This data repository is used by CHURN for retrospective studies about quality of care ${ }^{25-28}$ as well as interventional studies to improve quality of care. ${ }^{29}$ This study included CHURN members who agreed to participate in a study to improve quality of care for depression in primary care using the Patient Health Questionnaire (PHQ) 9, as well as CHURN members who agreed to be included in a comparison group that was not using the PHQ-9-this analysis examined practice patterns before the CHRUN members' participation in that interventional study. The study was granted exempt status by the institutional review board of the principal investigator's (JMG) local institution, St. Francis Hospital in Wilmington, DE.

This study included 209 providers in 40 family medicine and general internal medicine offices in 17 US states. The characteristics of these offices and providers are shown in Table 1 . The majority of providers were in family medicine practices. $\mathrm{Al}$ most half of the practice offices had 5 or fewer providers; only $12 \%$ of offices had $\geq 20$ providers.

For each participating practice we identified active adult ( $\geq 18$ years of age) patients who received a new diagnosis of depression during the first 9 months of the 1-year study period (17 October 2006 to 16 October 2007). "Active patient" was operationally defined as a patient who had at least 
Table 1. Provider Characteristics $(n=209)$

\begin{tabular}{lc}
\hline Characteristics & $\mathrm{n}(\%)$ \\
\hline Provider type & \\
Physician & $165(79)$ \\
Mid-level providers & $44(21)$ \\
Specialty & \\
Family medicine & $113(54)$ \\
Internal medicine & $83(40)$ \\
Other specialties & $13(6)$ \\
Location & \\
Urban & $56(27)$ \\
Suburban & $134(64)$ \\
Rural & $19(9)$ \\
Practice Size (providers, n) & \\
1-5 & $96(46)$ \\
$6-10$ & $48(23)$ \\
$11-20$ & $40(19)$ \\
$>20$ & $25(12)$ \\
\hline
\end{tabular}

one office visit to the study provider during the study year. Individuals who were diagnosed during the final 3 months of the study year were not included because there was insufficient time to observe treatment patterns. Diagnoses were operationally defined by the presence of International Classification of Diseases (ICD) 9 codes, including major depressive disorder (ICD-9 296.2 or 296.3) or depression not otherwise specified (ICD-9 311). We did not include persons who had been diagnosed only with dysthymic disorder, mixed depression/anxiety (ICD-9 300.4), or adjustment disorder with depressed mood (ICD-9 309.0, 309.1, or 309.28) because these represent more minor forms of depression for which the benefit of medication is less certain. ${ }^{30} \mathrm{We}$ also excluded patients with a recorded diagnosis of mania (ICD-9 296.0), bipolar disorder (ICD-9 296.4 to 8), or schizophrenia (ICD-9 295) because it was thought that these patients would be treated differently, including a higher rate of treatment by psychiatrists. "New diagnosis" of a depressive episode was operationally defined as having no active diagnosis of depression and no prescription of any antidepressant medication during the 6 months preceding the index diagnosis. Patients who had no office visit before the index depression diagnosis were excluded because this could represent either a new episode of depression or the entry of an established diagnosis of depression for a new patient. Using this method we identified a cohort of 1513 patients who met the criteria for a new diagnosis of depression during the study period.

For each patient in this cohort we determined the presence or absence of 1 of 6 comorbid medical conditions: diabetes mellitus (ICD-9 code 250.xx); CHD (ICD-9 code 410.xx-414.xx); congestive heart failure (ICD-9 code 428.xx); CVD (ICD-9 codes 430, 431.xx-437.xx); COPD (ICD-9 codes 491.1X-491.2X, 492.XX, 494.XX, and 496.XX); or cancer (ICD-9 codes 140.xx-209.xx, except for 173.xx [nonmelanoma skin cancer]). To be considered comorbid with depression, the medical condition had to be an active diagnosis in the EHR problem list at the time of the index diagnosis of depression.

Our main outcome variable was the prescription of an antidepressant medication, as defined by the EHR medication list. We excluded tricyclic antidepressants (TCAs) and trazodone from the definition of antidepressant medications because these medications are usually used for reasons other than depression. For the remaining medications we included any medication that was prescribed at or after the diagnosis of the episode of depression up to the end of the study period. Because the study period was 1 year and we only included persons diagnosed $\geq 3$ months before the end of the study period, the length of time each patient was observed after diagnosis ranged from 3 to 12 months.

We also examined whether or not patients had been prescribed a "minimum recommended dose" of antidepressant medication at any point during treatment. Minimum doses for each antidepressant medication were based on the lower limit of the dose range recommended by published guidelines for treatment of depression. ${ }^{31}$ Finally, we examined whether or not patients were prescribed a "full dose" of antidepressant medication at any point during treatment; "full dose" was defined as the upper limit of the usual dose range recommended by published guidelines for treatment of depression. ${ }^{31}$ Table 2 shows our definition of minimum and full doses for each antidepressant medication included in the outcomes. These medications were categorized by class, including selective serotonin reuptake inhibitors (SSRIs), serotonin-norepinephrine reuptake inhibitors, or other antidepressants (bupropion, mirtazapine and nefazodone). No patients were taking monoamine oxidase inhibitors, so these medications were not included in the table. 
Table 2. Minimum and Full Doses of Antidepressant Medication and Proportion of Patients on each Medication $(\mathrm{n}=1163)$

\begin{tabular}{|c|c|c|c|}
\hline Medication Category & Total Patients on Medication (n [\%]) & Minimum Dose (mg) & Full Dose (mg) \\
\hline \multicolumn{4}{|c|}{ Selective serotonin reuptake inhibitors } \\
\hline Citalopram & $290(24.9)$ & 20 & 40 \\
\hline Escitalopram & $261(22.4)$ & 10 & 20 \\
\hline Fluoxetine & $226(19.7)$ & 20 & 40 \\
\hline Paroxetine & $66(5.7)$ & 20 & 40 \\
\hline Sertraline & $156(13.4)$ & 50 & 100 \\
\hline \multicolumn{4}{|c|}{ Serotonin-norepinephrine reuptake inhibitors } \\
\hline Duloxetine & $72(6.2)$ & 30 & 60 \\
\hline Venlafaxine & $78(6.7)$ & 75 & 150 \\
\hline \multicolumn{4}{|l|}{ Other } \\
\hline Bupropion & $209(18.0)$ & 150 & 300 \\
\hline Mirtazapine & $23(2.0)$ & 15 & 30 \\
\hline Nefazodone & $1(0.1)$ & 300 & 600 \\
\hline
\end{tabular}

\section{Analysis}

Dichotomous variables were created for the main outcome variable (being prescribed any antidepressant medication) as well as the variables of being prescribed a minimum dose or being prescribed a full dose of medication. The 2 dose outcomes were analyzed only for persons who had been on medication for at least 3 months before the end of the study year $(\mathrm{n}=1163)$ to allow time for the treating physicians to increase antidepressant medication to a stable dose. For each outcome the proportion was compared for persons who had and did not have each of the comorbid conditions as well as for who had and did not have any of the 6 conditions. Odds ratios (ORs) and 95\% CIs were calculated for each comparison after controlling for age and sex using logistic regression models. We also conducted an analysis based on the number of comorbidites. We categorized persons as having none versus 1 versus $\geq 2$ comorbitidies and compared outcomes for these 3 categories, again calculating ORs and 95\% CIs for each comparison after controlling for age and sex, as described above.

\section{Results}

Table 3 shows the characteristics of the study population, including comorbidities by age and sex. Of the 1513 patients who had new episodes of depression, $20.7 \%$ had 1 of the 6 comorbid conditions;

Table 3. Characteristics of the Study Population $(n=1513)$

\begin{tabular}{|c|c|c|c|c|c|c|}
\hline \multirow[b]{2}{*}{ Comorbid Condition } & \multirow[b]{2}{*}{$\begin{array}{l}\text { Total with } \\
\text { Comorbidity }\end{array}$} & \multicolumn{3}{|c|}{ Age Distribution (Years) } & \multicolumn{2}{|c|}{ Gender Distribution } \\
\hline & & $\begin{array}{c}<40 \\
(\mathrm{n}=566)\end{array}$ & $\begin{array}{c}40-59 \\
(\mathrm{n}=601)\end{array}$ & $\begin{aligned} & \geq 60 \\
(\mathrm{n} & =346)\end{aligned}$ & $\begin{array}{l}\text { Women } \\
(\mathrm{n}=967)\end{array}$ & $\begin{array}{c}\text { Men } \\
(\mathrm{n}=546)\end{array}$ \\
\hline Coronary heart disease & $79(5.2)$ & $1(1.3)$ & $17(21.5)$ & $61(77.2)$ & $41(51.9)$ & $38(48.1)$ \\
\hline Cerebrovascular disease & $46(3.0)$ & $0(0.0)$ & $6(13.0)$ & $40(87.0)$ & $29(63.0)$ & $17(37.0)$ \\
\hline Diabetes & $172(11.4)$ & $17(9.9)$ & $66(38.4)$ & $89(51.7)$ & $101(58.7)$ & $71(41.3)$ \\
\hline Cancer & $55(3.6)$ & $1(1.8)$ & $15(27.3)$ & $39(70.9)$ & $34(61.8)$ & $21(38.2)$ \\
\hline Congestive heart failure & $21(1.4)$ & $0(0.0)$ & $2(9.5)$ & $19(90.5)$ & $13(61.9)$ & $8(38.1)$ \\
\hline $\begin{array}{l}\text { Chronic obstructive pulmonary } \\
\text { disease }\end{array}$ & $51(3.4)$ & $0(0.0)$ & $14(27.5)$ & $37(72.5)$ & $30(58.8)$ & $21(41.2)$ \\
\hline \multicolumn{7}{|l|}{ Comorbidities } \\
\hline 0 & $1,200(79.3)$ & $548(45.7)$ & $498(41.5)$ & $154(12.8)$ & $783(65.3)$ & $417(34.8)$ \\
\hline 1 & $224(14.8)$ & $17(75.9)$ & $88(39.3)$ & $119(53.1)$ & $133(59.4)$ & $91(40.6)$ \\
\hline$\geq 2$ & $89(5.9)$ & $1(1.1)$ & $15(16.9)$ & $73(82.0)$ & $51(57.3)$ & $38(42.7)$ \\
\hline
\end{tabular}

All data shown as n (\%). 


\begin{tabular}{|c|c|c|c|c|}
\hline \multirow[b]{2}{*}{ Comorbidity } & \multicolumn{2}{|c|}{ Patients Who Were Prescribed an Antidepressant (\%) } & \multicolumn{2}{|c|}{$\begin{array}{c}\text { Likelihood of Being } \\
\text { Prescribed } \\
\text { Antidepressant }\end{array}$} \\
\hline & Patients with Comorbidity & Patients without Comorbidity & Odds Ratio* & $95 \% \mathrm{CI}$ \\
\hline Coronary heart disease & 67.1 & 77.4 & 0.72 & $0.43-1.20$ \\
\hline Cerebrovascular disease & 65.2 & 77.2 & 0.70 & $0.37-1.33$ \\
\hline Diabetes & 73.8 & 77.3 & 0.96 & $0.66-1.40$ \\
\hline Cancer & 63.6 & 77.4 & 0.61 & $0.34-1.10$ \\
\hline Congestive heart failure & 71.4 & 76.9 & 0.96 & $0.37-2.54$ \\
\hline Chronic obstructive pulmonary disease & 72.6 & 77.0 & 0.97 & $0.51-1.84$ \\
\hline Any comorbidity & 72.2 & 78.1 & 0.87 & $0.63-1.21$ \\
\hline
\end{tabular}

*Odds ratios for patients who have a comorbidity compared to patients who do not have a comorbidity, adjusted for age and sex.

diabetes was the most common $(11.4 \%)$, followed by $\mathrm{CHD}(5.2 \%)$, cancer $(3.6 \%)$, COPD $(3.4 \%)$, and CVD (3.0\%). Approximately $6 \%$ had $\geq 2$ of these comorbidities. The majority of patients were aged $\geq 40$ years $(63 \%)$ and were women $(64 \%)$. Comorbidities were more common among men and older persons; $82 \%$ of patients with $\geq 2$ comorbidities were aged $\geq 60$ years.

Overall, 1163 patients were prescribed an antidepressant medication, representing $77.4 \%$ of patients who experienced a new episode of depression. The most common class of antidepressants prescribed was the SSRI class, and citalopram was the most commonly prescribed individual medication. As shown in Table 4, the likelihood of being prescribed an antidepressant medication was not significantly different for persons who had a comorbid medical condition compared with those who did not have a comorbid medical condition, after controlling for age and sex (adjusted OR, 0.87; $95 \%$ CI, 0.63-1.21). Also, there were no significant differences according to the presence or absence of any of the individual comorbid medical conditions. However, persons who had multiple comorbid conditions were significantly less likely to be prescribed an antidepressant medication than those who had no comorbid conditions (adjusted OR, 0.58; 95\% CI, 0.35-0.96).

Of those patients who received prescriptions for antidepressant medications, $91.3 \%$ were prescribed at least the minimally recommended dose of medication. Table 5 shows the likelihood of being prescribed the minimal dose of antidepressant medication by each of the comorbid conditions. After controlling for age and sex, there was no significant difference in the likelihood of being prescribed the minimally recommended dose of antidepressant medication for those who had or who did not have comorbid conditions (adjusted OR, 0.68; 95\% CI, $0.40-1.14)$. Also, there were no significant differences according to the presence or absence of any of the individual comorbid medical conditions or for persons with multiple comorbid conditions.

Of those patients who received prescriptions for antidepressant medications, $37.7 \%$ were prescribed full doses of medication. Table 5 shows the likelihood of being prescribed full doses of antidepressant medication by each of the comorbid conditions. Patients were less likely to be prescribed a full dose of antidepressant medication if they had CVD (adjusted OR, 0.26; 95\% CI, 0.08-0.88). However, there were no significant differences in the prescription of full doses of medication for persons who had any other individual comorbid medical condition, for persons who had any comorbid condition (adjusted OR, 0.88; 95\% CI, 0.611.25 ), or for persons with multiple comorbid conditions (adjusted OR, 0.60; 95\% CI, 0.30-1.20).

\section{Discussion}

Depression is more common among patients who have a significant medical comorbidity, ${ }^{5}$ and its presence may increase morbidity and mortality from the comorbid condition. Depression is associated with worse glycemic control, ${ }^{16}$ higher risk of complications, ${ }^{32}$ and higher mortality ${ }^{17}$ among persons who have diabetes. Depression is also associated with higher mortality among persons who have had a myocardial infarction $(\mathrm{MI})^{33}$ or stroke $^{21,34}$ and in patients with cancer. ${ }^{13,22}$

There is also some evidence that the treatment of depression improves outcomes for comorbid 


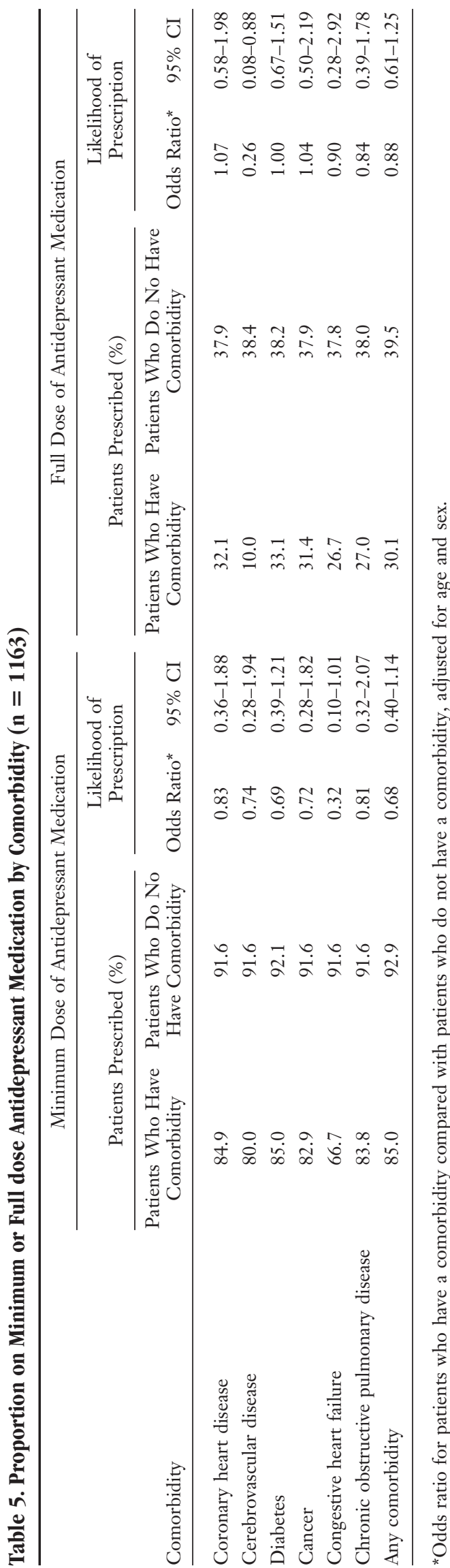

conditions. A small study showed that treatment of depression after an MI led to fewer subsequent cardiac events. ${ }^{35}$ A post hoc analysis of a larger, randomized trial showed a reduction in death and recurrent MI when patients were treated with antidepressant medications after an $\mathrm{MI},{ }^{36}$ although the benefit was seen only for those taking SSRIs (not those taking TCAs), and the benefit was not seen in the larger, randomized trial, which included patients who had been given psychotherapy but not antidepressant medications. ${ }^{37}$ Both SSRI and TCA antidepressants have been found to reduce mortality among patients who have had a stroke. ${ }^{38}$ One study showed that the treatment of depression among patients who have diabetes was associated with better blood pressure control and borderline better glycemic control. ${ }^{16}$

Given this evidence, one might expect that primary care physicians would be more likely to prescribe antidepressant medications for depressed patients if they had significant medical comorbidities. Our results suggest that this is not the case. Primary care physicians in this study were no more likely to prescribe pharmacologic treatment to patients with medical comorbidities than to those without. They were also no more likely to prescribe higher doses of antidepressant medication for patients who had medical comorbidities. In fact, in some situations physicians were significantly less aggressive in the prescription of antidepressant medications for patients with medical comorbidites. After controlling for age and sex, patients who had multiple comorbidities were less likely to be prescribed antidepressant medications, and patients who had CVD were less likely to be prescribed full doses of these medications.

At first glance, these results may seem surprising-and disappointing. But they must be interpreted with an understanding of the uncertainty in the evidence regarding the impact of treating depression in patients with comorbidites. Although there is overwhelming evidence that depression occurs at a higher rate and is associated with greater morbidity and mortality in patients who have significant medical comorbidities, there is some controversy about whether treatment with antidepressants improves medical outcomes. For example, while one study showed improved medical outcomes when persons with diabetes were treated for their depression, ${ }^{16} 2$ studies showed no significant improvement in diabetes control when comorbid 
depression was treated, ${ }^{39,40}$ and another study showed worse glycemic control with pharmacologic treatment. ${ }^{41}$ The evidence is similarly conflicting for persons who have heart disease. Although several studies have shown improved morbidity and mortality among patients who were treated for depression after an MI, ${ }^{35,36}$ other studies have shown no such benefit. ${ }^{42}$ In fact, some studies have suggested that antidepressant medications may increase medical risk in some patients: one study found a higher rate of stroke and allcause mortality among patients taking SSRIs and higher all-cause mortality among patients taking TCAs. ${ }^{24}$ Other studies have suggested that TCAs can worsen outcomes for patients after an $\mathrm{MI}^{43}$ This evidence may concern primary care physicians enough so that they are cautious when prescribing antidepressant medications to patients with these comorbidities.

However, the preponderance of evidence suggests that it is not necessary to be overly cautious when prescribing for patients who have medical comorbidities. Most studies have demonstrated that SSRIs are safe and effective in persons who have both $\mathrm{CAD}^{10,44}$ and stroke. ${ }^{45-47}$ Even for studies that show an association of antidepressant medication with worse outcomes, authors have suggested that it may be the depression rather than the antidepressant medication that is responsible for these outcomes. ${ }^{48,49}$ Current guidelines recommend vigilance when diagnosing and treating depression in patients who have comorbid medical conditions. For example, the American Heart Association guidelines specifically say that "whether depression affects cardiac outcomes directly or indirectly, the need to screen and treat depression is imperative."10

This study must be interpreted in the context of potential limitations. For example, this study shared certain limitations common to EHR-based research. First, because all data were extracted from the EHR, data that was not entered into the primary care office's EHR were not captured. This could include antidepressant medications that had been prescribed by outside providers and either not disclosed to the primary care provider or not entered by the primary care provider in the record, or the use of samples of medications that were not captured as electronic prescriptions in the record. These errors would result in an underestimation of antidepressant prescriptions. Conversely, pre- scribed medications could have been overestimated if they had been discontinued but not removed from the medication list. These problems are of relatively less concern in this study given its focus on new treatment episodes rather than maintenance-phase treatment. Second, we could not reliably assess the use of combined antidepressant medications (for example, low-dose bupropion plus low-dose citalopram) from prescription data. Therefore, it is likely that we underestimated the proportion of patients who were receiving more aggressive treatment because we did not include combination therapy as more aggressive treatment. Third, the analyses examined only the prescription of antidepressant medication, not pharmacy fill records or medications that were actually taken by patients. This was a reasonable limitation in a study that assessed physicians' treatment decisions. Finally, the study was limited to primary care practices that were participating in an EHR-based research collaborative, and specifically those practices that had agreed to participate in a study using the PHQ-9; therefore, the results may not be generalizable to other practice settings. However it is important to note that the study represents behavior that occurred before the PHQ-9 intervention was implemented (so the intervention could not have influenced the results), and that we also included practices that did not participate in the PHQ-9 intervention but had agreed to be included in a nonintervention comparison group. A previous observational study that included primary care and specialty physicians who were not involved in any interventional study found similar results. ${ }^{25}$

More importantly, this study design could not address the primary care context of competing demands ${ }^{50}$ and patient preferences. In the presence of one or more chronic health problems, physicians and patients formally and informally set priorities for treatment and may focus on one problem while leaving others "untreated." ${ }^{51-54}$ In this study we found a relatively high overall rate of antidepressant medication prescription (77\%) in patients who had comorbid medical conditions. It is possible that this is a relative "ceiling" for medication use and that the remaining $23 \%$ represents patients for whom additional medication prescriptions are not desired or have a lower relative priority. These patients may be using multiple medications for their comorbid condition(s) and additional medications may be considered as too burdensome in 
terms of cost and potential side effects. This is supported by the fact that persons who have multiple comorbidities were significantly less likely to be prescribed medications. It is also possible that nonpharmacologic depression treatment is preferred or used at a higher rate among these patients. Psychotherapy may be seen as less burdensome to patients who are already taking multiple medications. Data about the use of psychotherapy were not available in our study. However, the evidence for psychotherapy is not necessarily better than the evidence for pharmacotherapy for patients with comorbidities. In fact, one study showed psychotherapy to be of little benefit in patients after a stroke, ${ }^{55}$ and another study found psychotherapy to be less effective than pharmacotherapy among patients with $\mathrm{CAD} .{ }^{44}$

\section{Conclusion}

This study found that primary care providers do not treat depression more aggressively in patients who have medical comorbidites, and, in fact, primary care providers sometimes treat these patients less aggressively. Although less-aggressive treatment may be appropriate in some cases, in other cases it may mean that patients are not being appropriately treated for their depression. This could not only result in unnecessary morbidity from the depression itself, but also higher morbidity from the medical condition. Future research about how the treatment of depression benefits medical comorbidities could be very helpful in guiding the treatment decisions of primary care providers, particularly qualitative studies that include exploration of treatment priorities and patient preferences.

The authors would like to thank Ms. Angela Grimes for her assistance with the preparation of data and Ms. Cheryl Mongillo for her assistance with manuscript preparation.

\section{References}

1. Kessler RC, Berglund P, Demler O, Jin R, Merikangas KR, Walters EE. Lifetime prevalence and ageof-onset distributions of DSM-IV disorders in the National Comorbidity Survey Replication. Arch Gen Psychiatry 2005;62:593-602.

2. Kessler RC, Chiu WT, Demler O, Merikangas KR, Walters EE. Prevalence, severity, and comorbidity of 12-month DSM-IV disorders in the National Comorbidity Survey Replication. Arch Gen Psychiatry 2005;62:617-27.

3. Klinkman MS, Okkes I. Mental health problems in primary care a research agenda. J Fam Pract 1998; 47:379-84.

4. Unutzer J, Katon W, Sullivan M, Miranda J. Treating depressed older adults in primary care: narrowing the gap between efficacy and effectiveness. Milbank Q 1999;77:225-56.

5. Katon W, Sullivan MD. Depression and chronic medical illness. J Clin Psychiatry 1990;51(Suppl):311; discussion, 12-4.

6. Egede LE, Zheng D, Simpson K. Comorbid depression is associated with increased health care use and expenditures in individuals with diabetes. Diabetes Care 2002;25:464-70.

7. Whyte EM, Mulsant BH, Vanderbilt J, et al. Depression after stroke: a prospective epidemiological study. J Am Geriatr Soc 2004;52:774-8.

8. Guck TP, Kavan MG, Elsasser GN, Barone EJ. Assessment and treatment of depression following myocardial infarction. Am Fam Physician 2001;64: 641-8.

9. Ormel J, Von Korff M, Burger H, et al. Mental disorders among persons with heart disease-results from World Mental Health surveys. Gen Hosp Psychiatry 2007;29:325-34.

10. Lichtman JH, Bigger JT Jr, Blumenthal JA, et al. Depression and coronary heart disease: recommendations for screening, referral, and treatment: a science advisory from the American Heart Association Prevention Committee of the Council on Cardiovascular Nursing, Council on Clinical Cardiology, Council on Epidemiology and Prevention, and Interdisciplinary Council on Quality of Care and Outcomes Research: endorsed by the American Psychiatric Association. Circulation 2008;118:1768-75.

11. Ziegelstein RC. Depression after myocardial infarction. Cardiol Rev 2001;9:45-51.

12. Patten SB, Williams JVA. Chronic obstructive lung diseases and prevalence of mood, anxiety, and substance-use disorders in a large population sample. Psychosomatics 2007;48:496-501.

13. Meyer HA, Sinnott C, Seed PT. Depressive symptoms in advanced cancer. Part 2. Depression over time; the role of the palliative care professional. Palliat Med 2003;17:604-7.

14. Massie M. Prevalence of depression in patients with cancer. J Natl Cancer Inst Monogr 2004;32:57-71.

15. Spiegel D. Cancer and depression. Br J Psychiatry Suppl 1996;(30):109-16.

16. Rush WA, Whitebird RR, Rush MR, Solberg LI, O'Connor PJ. Depression in patients with diabetes: does it impact clinical goals? J Am Board Fam Med 2008;21:392-7.

17. Egede LE, Nietert PJ, Zheng D. Depression and all-cause and coronary heart disease mortality among adults with and without diabetes. Diabetes Care 2005;28:1339-45.

18. Lin EHB, Heckbert SR, Rutter CM, et al. Depres- 
sion and increased mortality in diabetes: unexpected causes of death. Ann Fam Med 2009;7:414-21.

19. Lauzon C, Beck CA, Huynh T, et al. Depression and prognosis following hospital admission because of acute myocardial infarction [see comment]. CMAJ 2003;168:547-52.

20. Carney RM, Freedland KE, Steinmeyer B, et al. Depression and 5-year survival following acute myocardial infarction: a prospective study. J Affect Disord 2008;109:133-8.

21. Jia H, Damush TM, Qin H, et al. The impact of poststroke depression on healthcare use by veterans with acute stroke. Stroke 2006;37:2796-801.

22. Watson M, Haviland JS, Greer S, Davidson J, Bliss JM. Influence of psychological response on survival in breast cancer: a population-based cohort study. Lancet 1999;354:1331-6.

23. Smith GF, Toonen TR. Primary care of the patient with cancer. Am Fam Physician 2007;75:1207-14.

24. Smoller JW, Allison M, Cochrane BB, et al. Antidepressant use and risk of incident cardiovascular morbidity and mortality among postmenopausal women in the Women's Health Initiative study. Arch Int Med 2009;169:2128-39.

25. Gill JM, Chen YX, Lieberman MI. Management of depression in ambulatory care for patients with medical co-morbidities: a study from a national electronic health record (EHR) network. Int J Psychiatry Med 2008;38:203-15.

26. Gill J, Chen YX. Quality of lipid management in outpatient care: a national study using electronic health records. Am J Med Qual 2008;23:75-381.

27. Gill JM, Fleischut P, Haas S, Pellini B, Crawford A, Nash DB. Use of antibiotics for adult upper respiratory infections in outpatient settings: a national ambulatory network study. Fam Med 2006;38:34954.

28. Gill JM, Foy AJ, Ling Y. Quality of outpatient care for diabetes mellitus in a national electronic health record network. Am J Med Qual 2006;21:13-7.

29. Gill JM, Chen YX, Glutting JJ, Diamond JJ, Lieberman MI. Impact of decision support in electronic medical records on lipid management in primary care. Popul Health Manag 2009;12:221-6.

30. Fournier JC, DeRubeis RJ, Hollon SD, et al. Antidepressant drug effects and depression severity: a patient-level meta-analysis. JAMA 2010;303:47-53.

31. Therapeutic Guidelines, Ltd. Therapeutic guidelines: psychotropic. 5 ed. North Melbourne: Therapeutic Guidelines, Ltd.; 2003.

32. de Groot M, Anderson R, Freedland KE, Clouse RE, Lustman PJ. Association of depression and diabetes complications: a meta-analysis. Psychosom Med 2001;63:619-30.

33. Frasure-Smith N, Lesperance F, Talajic M. Depression following myocardial infarction. Impact on 6-month survival. JAMA 1993;270:1819-25.

34. Morris PL, Robinson RG, Samuels J. Depression, introversion and mortality following stroke. Aust N J Z Psychiatry 1993;27:443-9.

35. Mohapatra PK, Kar N, Kar GC, Behera M. Effectiveness of sertraline in treatment of depression in a consecutive sample of patients with acute myocardial infarction: six-month prospective study on outcome. Clin Pract Epidemiol Ment Health 2005;1:26.

36. Taylor CB, Youngblood ME, Catellier D, et al. Effects of antidepressant medication on morbidity and mortality in depressed patients after myocardial infarction [see comment]. Arch Gen Psychiatry 2005;62:792-8.

37. Berkman LF, Blumenthal J, Burg M, et al. Effects of treating depression and low perceived social support on clinical events after myocardial infarction: the Enhancing Recovery in Coronary Heart Disease Patients (ENRICHD) randomized trial [see comment]. JAMA 2003;289:3106-16.

38. Jorge RE, Robinson RG, Arndt S, Starkstein S. Mortality and post-stroke depression: a placebo-controlled trial of antidepressants. Am J Psychiatry 2003;160:1823-9.

39. Lustman P, Freedland K, Griffith L, Clouse R. Fluoxetine for depression in diabetes: a randomized double-blind placebo-controlled trial. Diabetes Care 2000;23:618-23.

40. Williams JW, Katon W, Lin EHB, et al. The effectiveness of depression care management on diabetesrelated outcomes in older patients. Ann Intern Med 2004;140:1015-24.

41. Lustman PJ, Griffith LS, Clouse RE, et al. Effects of nortriptyline on depression and glycemic control in diabetes: results of a double-blind, placebo-controlled trial. Psychosom Med 1997;59:241-50.

42. Thombs BDP, de Jonge PP, Coyne JCP, et al. Depression screening and patient outcomes in cardiovascular care: a systematic review. JAMA 2008;300: 2161-71.

43. Glassman AH, Roose SP, Bigger JT Jr. The safety of tricyclic antidepressants in cardiac patients. Riskbenefit reconsidered. JAMA 1993;269:2673-5.

44. Lespérance F, Frasure-Smith N, Kosyzcki D, et al. Effects of citalopram and interpersonal psychotherapy on depression in patients with coronary artery disease. JAMA 2007;297:367-79.

45. Kharofa J, Sekar P, Haverbusch M, et al. Selective serotonin reuptake inhibitors and risk of hemorrhagic stroke. Stroke 2007;38:3049-51.

46. Bak S, Tsiropoulos I, Kjaersgaard JO, et al. Selective serotonin reuptake inhibitors and the risk of stroke: a population-based case-control study. Stroke 2002; 33:1465-73.

47. de Abajo FJ, Jick H, Derby L, Jick S, Schmitz S. Intracranial haemorrhage and use of selective serotonin reuptake inhibitors. Br J Clin Pharmacol 2000; 50:43-7.

48. O'Connor CM, Jiang W, Kuchibhatla M, et al. Anti- 
depressant use, depression, and survival in patients with heart failure. Arch Intern Med 2008;168:2232-7.

49. Tata LJ, West J, Smith C, et al. General population based study of the impact of tricyclic and selective serotonin reuptake inhibitor antidepressants on the risk of acute myocardial infarction. Heart 2005;91:465-71.

50. Klinkman MS. Competing demands in psychosocial care. A model for the identification and treatment of depressive disorders in primary care [see comment]. Gen Hosp Psychiatry 1997;19:98-111.

51. Rost K, Nutting P, Smith J, Coyne JC, CooperPatrick L, Rubenstein L. The role of competing demands in the treatment provided primary care patients with major depression. Arch Fam Med 2000; 9:150-4.
52. Nutting PA, Rost K, Smith J, Werner JJ, Elliot C. Competing demands from physical problems: effect on initiating and completing depression care over 6 months. Arch Fam Med 2000;9:1059-64.

53. Parchman ML, Pugh JA, Romero RL, Bowers KW. Competing demands or clinical inertia: the case of elevated glycosylated hemoglobin. Ann Fam Med 2007;5:196-201.

54. Bayliss EA, Edwards AE, Steiner JF, Main DS. Processes of care desired by elderly patients with multimorbidities. Fam Pract 2008;25:287-93.

55. Lincoln NB, Flannaghan T. Cognitive behavioral psychotherapy for depression following stroke: a randomized controlled trial. Stroke 2003;34:111-5. 